\title{
Controlling for homophone polarity and prime-target relatedness in the cross-modal lexical decision task
}

\author{
JONATHAN PICOULT and MARCIA K. JOHNSON \\ Princeton University, Princeton, New Jersey
}

\begin{abstract}
Access of alternative meanings of ambiguous words was investigated with a cross-modal lexical decision task. We considered two factors that may have been inadequately controlled in previous experiments, homophone polarity and prime-target relatedness. We used both nonpolar homophones with two nearly equiprobable senses and polar homophones with one clearly dominant sense. Polarity ratings were derived from homophone familiarity norms obtained by Kreuz (1987). We also equated prime-target relatedness across items for dominant and subordinate meanings of the homophones using norms that we collected. Sentence contexts biased the dominant meanings of the homophones. Under these conditions, there was a small but significant priming effect, and priming of the subordinate meaning was not significantly affected by homophone polarity.
\end{abstract}

The cross-modal lexical decision task has been a primary procedure for investigating lexical access. A major issue addressed in previous research has been whether lexical access to alternative meanings of ambiguous words is context-dependent or initially exhaustive, with context operating on "postaccess" processes. Past cross-modal studies, however, may have failed to adequately control the polarity of ambiguous items (i.e., the degree to which one word sense dominated over the other) and the relatedness of the ambiguous items to the lexical targets (Holmes, Arwas, \& Garrett, 1977; Onifer \& Swinney, 1981; Seidenberg, Tanenhaus, Leiman, \& Bienkowski, 1982; Swinney, 1979; Tabossi, 1988; Tabossi, Colombo, \& Job, 1987; Tanenhaus, Leiman, \& Seidenberg, 1979).

To control polarity, for example, Onifer and Swinney (1981) presented subjects with homographs and homophones and asked them to describe the first meaning that came to mind. The words that elicited one common interpretation from over $75 \%$ of the subjects, and a different common interpretation from less than $25 \%$ of the subjects, were deemed "polar" and used in the experiment. The problem with this procedure is that it may incorrectly label some nearly equiprobable (nonpolar) ambiguous words as polar. Consider a word with two senses of nearly equal frequencies. If one sense is just slightly more familiar than the other, it could be chosen as the dominant meaning by the $75 \%$ of the subjects necessary in the Onifer and Swinney pretest, and would therefore be designated as "polar." Priming of subordinate meanings of supposedly polar homographs would then provide an artifactual demonstration of exhaustive lexical access. If Onifer and Swinney labeled nearly equiprobable ambiguities as polar, their exhaustive access results would be less convincing.

This research was supported in part by NIH Grant 1-R01 AG09253. We would also like to thank Tina Loose for her help with statistical analyses and Sam Glucksberg for his helpful comments on an earlier draft. Correspondence may be addressed to Marcia K. Johnson, Department of Psychology, Green Hall, Princeton University, Princeton, NJ 08544-1010.
In the present experiment, we sought to control polarity by using the homophone familiarity ratings reported by Kreuz (1987). Kreuz's subjects were specifically asked to rate the familiarity of printed homophones. This provided independent ratings of both the dominant and the subordinate senses of the homophones.

Not only should the relative familiarity of dominant and subordinate meanings of the ambiguous items be clearly specified, so too should the strength of association between each meaning and the corresponding lexical target. However, many cross-modal researchers (Onifer \& Swinney, 1981; Seidenberg et al., 1982; Swinney, 1979; Tanenhaus et al., 1979) have merely noted that experimental targets were "related" or were "associates" of their respective ambiguous words, though they cite no source for such measures of relatedness. If, on the average, the dominantrelated lexical targets are more strongly associated to the ambiguous word than their subordinate counterparts (or vice versa) are, then the priming effect will not be a fair measure of access to the two potential meanings of the item.

In the present experiment, we used a pretest to obtain norms of association for the experimental homophones. The relatedness of the dominant targets and subordinate targets to the homophone was then equated. With the target-relatedness factor controlled, any priming effects obtained in this experiment should be a "purer" measure of lexical access than those obtained in past research.

\section{METHOD}

\section{Subjects}

Forty undergraduate students at Princeton University served as paid volunteers; all were native English speakers.

\section{Design and Materials}

Critical items used in this study were derived from a list of homophones compiled by Kreuz (1987). Using his familiarity ratings, a polarity ratio (PR) was calculated for each homophone pair, ranging from perfectly polar, $\mathrm{PR}=0.01$ (one sense much more familiar than the other), to perfectly nonpolar, $\mathrm{PR}=1.00$ (senses nearly equal in familiarity). Twenty nonpolar (i.e., nearly equiprobable) homophone pairs $(P R=$ $.85-1.00)$ and 20 polar pairs $(P R=.51-.69)$ were chosen for use in the experiment. 
For each homophone, a sentence was constructed that incorporated a dominantly biased context before the ambiguous word. Five of the sentences (indicated by an asterisk in the Appendix) were taken from Onifer and Swinney (1981). Note that for all but one of the nonpolar items there was always one meaning that had a slight advantage in familiarity. For the one nonpolar homophone pair that was calculated to be perfectly equiprobable, a dominant sense was picked randomly. A set of four lexical targets was constructed for each homophone. One of these four was highly related to the dominant meaning of the item, and another was highly related to the secondary meaning of the item.

These two experimental lexical targets were obtained in a pretest questionnaire completed by 63 Princeton University undergraduates, none of whom participated in the actual experiment. Two questionnaire forms were used. Each listed 40 words and asked subjects to write down the first word they thought of in response to each stimulus. Note that each form of the pretest included only one member from a homophone pair, so the fact that the words were aurally ambiguous was not particularly salient to pretest subjects. The word associates receiving the highest percentage of responses were then used as experimental lexical targets (except for a few instances in which the second most common response was used because the most common response conflicted with words in the experimental sentence). This percentage was equated for the dominan and subordinate targets, so that on the average, neither condition had an advantage in target relatedness. The remaining two lexical targets were controls; each was matched in frequency (Francis \& Kucera, 1982) and letter length with its respective experimental target.

The 40 experimental sentences were mixed pseudorandomly with 41 filler sentences whose lexical targets were nonwords, so that subjects responses to the lexical decision task were nearly evenly split between the affirmative and the negative. A list of the experimental sentences and their accompanying lexical targets is given in the Appendix.

The 81 sentences were recorded on a four-track audio tape. A $1000-\mathrm{Hz}$ signal was placed on a separate channel of the audio tape exactly coincident with the offset of the ambiguous word in each experimental sentence (and with the offset of a pseudorandomly chosen word in filler sentences). These signals, which were inaudible to the subject, triggered a Commodore Pet 2001 computer to present the appropriate lexical target and to initiate a timing mechanism that was terminated by the subject's buttonpress.

\section{Procedure}

The 81 sentences were presented to the subjects binaurally over a pair of headphones. They were instructed to listen carefully to, and to comprehend, each sentence. The subjects were told that they had a second, equally important task. It was explained that a string of letters would appear on the visual display screen at some point during each sentence. The subjects were to indicate, as quickly as possible, whether or not each letter string they saw formed a word; they were to do so by pressing one of the two buttons on which they rested their hands throughout the experiment. They were told that they would be asked some comprehension questions at the conclusion of the experiment. Therefore, they were cautioned to continue listening to each sentence even while making their lexical decisions.

\section{RESULTS}

The individual data were subjected to a repeated measures analysis of variance. In order to reduce variability, data points 2.5 standard deviations above and below the mean for all subjects for each condition were excluded before individual subject means were computed. Overall, $6.4 \%$ of all scores were dropped, with no condition losing less than $5.6 \%$ or more than $7.1 \%$ of its data. Mean response times for each of the eight experimental conditions are presented in Table 1 . There was a main effect of target type, with response times for experimental lexical targets faster than those for control targets $[F(1,39)$ $\left.=13.71, M S_{\mathrm{e}}=1,281.30, p<.001\right]$. There was no significant two-way interaction between word sense and target; dominant and subordinate senses exhibited equal priming $\left[F(1,39)=1.05, M S_{\mathrm{e}}=1,367.42, p>.10\right]$. (See Figure 1.) There was also no significant three-way interaction between sense, target, and polarity $[F(1,39)=0.02$, $\left.M S_{\mathrm{e}}=1,267.02, p>.10\right]$. Separate analysis of the polar and nonpolar data showed that the main effect of target type was significant for both conditions $[F(1,39)=$ $7.79, M S_{\mathrm{e}}=1,651.16, p<.01$, and $F(1,39)=4.12, M S_{\mathrm{e}}$ $=1,332.16, p<.05$, respectively]

\section{DISCUSSION}

We observed a priming effect that was consistent across the dominant and subordinate conditions (see Figure 1). The priming effect was not sensitive to polarity and was obtained when prime-target relatedness was equated for dominant and subordinate targets. This experiment supports the exhaustive access model in its strongest form; even a polarized homophone, when placed in a dominantly biased context, primes both its dominant and its subordinate meaning.

In addition to exhaustive priming, this experiment yielded other interesting results: (1) Subjects' response times in this experiment were much faster than those in other studies (see Figure 2a), and (2) the average size of the priming effect in this experiment was smaller than the size of the priming effects in other studies, both in absolute terms (see Figure $2 b$ ) and as a percentage of the baseline control conditions.

When evaluated in absolute terms, the amount of priming appears to be related to a study's overall response times. Experiments with slower overall response times may be more susceptible to postaccess influences that could artificially enlarge the priming effect. Such studies may not measure lexical access uncontaminated by postaccess processes. Hence, our small priming effect could, in part, be related to our overall "fast" results.

The correlation between overall response time and amount of priming is not as clear-cut when priming is considered as a percentage of baseline response times. Nonetheless, even from this perspective, the amount of priming does vary (e.g., $3.2 \%$ of baseline in our experiment and $9.2 \%$ of baseline in Onifer \& Swinney, 1981). Such variations might arise from differences across studies in prime-target relatedness. Recall that past experimenters chose their lexical targets without the use of pretest norms. In searching for an appropriate experimental lexical target, an experimenter may choose an ambiguity-target pair that is well linked bidirectionally (e.g., STAKE - PEG). That is, the ambiguous word primes the target, but the target also primes the ambiguous word,

Table 1

Mean Response Times (in Milliseconds) for Lexical Decisions Made in Response to Words Related to the Dominant and Subordinate Interpretations of Polar and Nonpolar Ambiguities or to Control Words in Sentential Contexts Biased Toward the Dominant Meaning of the Ambiguity

\begin{tabular}{|c|c|c|c|c|c|c|c|c|c|}
\hline \multirow[b]{3}{*}{ Lexical Target } & \multirow[b]{3}{*}{ Type } & \multicolumn{8}{|c|}{ Homophone Polarity } \\
\hline & & \multicolumn{4}{|c|}{ Polar } & \multicolumn{4}{|c|}{ Nonpolar } \\
\hline & & Mean RT & $S D$ & $\%$ Errors & $\begin{array}{c}\text { Amount of } \\
\text { Priming }\end{array}$ & Mean RT & $S D$ & $\%$ Errors & $\begin{array}{c}\text { Amount of } \\
\text { Priming }\end{array}$ \\
\hline Dominant Meaning & $\begin{array}{l}\text { Experimental } \\
\text { Control }\end{array}$ & $\begin{array}{l}455 \\
469\end{array}$ & $\begin{array}{l}89.46 \\
81.63\end{array}$ & $\begin{array}{l}1.0 \\
0.5\end{array}$ & 14 & $\begin{array}{l}440 \\
447\end{array}$ & $\begin{array}{l}79.33 \\
81.25\end{array}$ & $\begin{array}{l}0.5 \\
0.5\end{array}$ & 7 \\
\hline Subordinate Meaning & $\begin{array}{l}\text { Experimental } \\
\text { Control }\end{array}$ & $\begin{array}{l}451 \\
473\end{array}$ & $\begin{array}{l}86.51 \\
76.97\end{array}$ & $\begin{array}{l}1.3 \\
0.5\end{array}$ & 22 & $\begin{array}{l}463 \\
479 \\
\end{array}$ & $\begin{array}{l}81.01 \\
72.11 \\
\end{array}$ & $\begin{array}{l}0.3 \\
0.5\end{array}$ & 16 \\
\hline
\end{tabular}




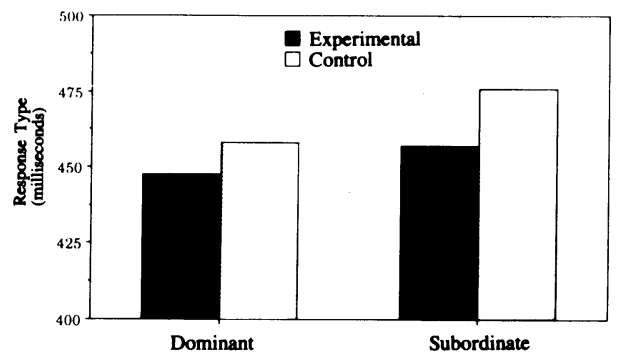

Figure 1. Mean response times for lexical decisions in response to targets in the dominant and subordinate conditions.

so any spread of activation from the two lexical entries would presumably intersect very quickly at some midpoint (see Glucksberg, Kreuz, \& Rho, 1986). Such backward priming would speed up subjects' responses to experimental targets, thereby producing larger priming effects.

In contrast, the pretest used in this experiment to obtain lexical targets may have yielded ambiguity-target pairs that were not so bidirectionally linked. By producing word associations in response to a written pretest, subjects are not apt to search for the "best" ambiguity-target pair. Rather, they presumably often generated a target that, though primed by the homophone, did not readily prime the homophone in a reciprocal manner (e.g., STAKE $\rightarrow$ HEART). Such ambiguity-target pairs would be less susceptible to backward priming, so the observed priming effect would be smaller. The sensitivity of prime-target pairs to backward priming in the present experiment, among others, could be measured in a standard lexical decision task with the lexical target as prime and the homophone as target.
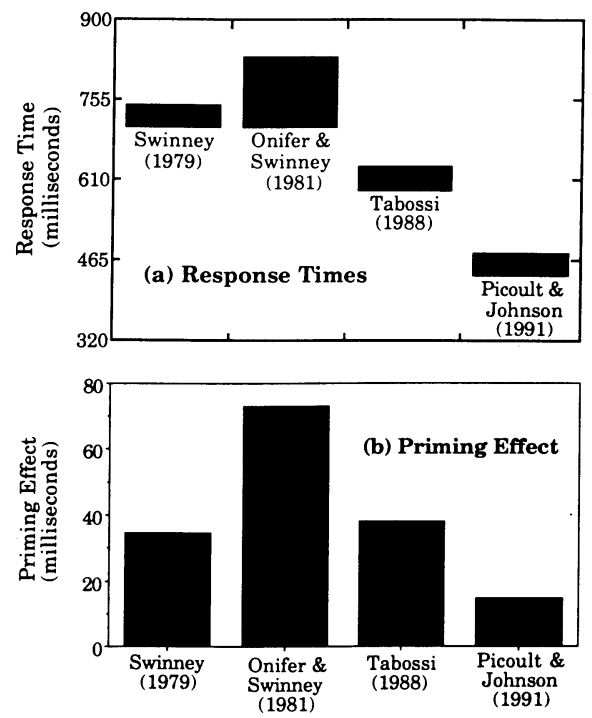

Figure 2. (a) Ranges of mean response times in several cross-modal lexical ambiguity experiments. (b) Mean size of priming effect in several cross-modal lexical ambiguity experiments.
Finally, it would be desirable in future studies to have the same items serve as both experimental and control targets across subjects. Although we and other investigators equated experimental and control items for frequency and length, there may be unknown differences between the two sets of items. In fact, Kreuz (1987) noted that words of equal frequency (Kưcera \& Francis, 1967) may differ in familiarity. Given the small priming effects obtained, as many uncontrolled factors as possible should be eliminated.

In summary, we did our best to "stack the deck" against exhaustive access-using dominantly biased contexts and truly polarized homophones-and yet, we still found evidence for equal access to dominant and subordinate meanings of polar homophones. Additionally, our extremely fast reaction times suggest that other studies' results may have been influenced by postaccess processing. Lastly, we have argued that choosing lexical targets, and equating them on relatedness to the ambiguous word, is an important aspect of the cross-modal procedure. Just as a mere 200-msec change in stimulus onset asynchrony can have enormous implications for a cross-modal task (Seidenberg et al., 1982; Tanenhaus et al., 1979), so too may small changes in target relatedness. Thus, it would be interesting to manipulate this factor in future studies. In any event, prime-target relatedness should be controlled in exploring the mechanisms of lexical ambiguity resolution.

\section{REFERENCES}

FrANCIS, W. N., \& KučERA, H. (1982). Frequency analysis of English usage: Lexicon and grammar. Boston: Houghton Mifflin.

Glucksberg, S., KreuZ, R. J., \& RHo, S. H. (1986). Context can constrain lexical access: Implications for models of language comprehension. Joumal of Experimental Psychology: Learning, Memory, \& Cognition, 12, 323-335.

Holmes, V. M., Arwas, R., \&arrett, M. F. (1977). Prior context and the perception of lexically ambiguous sentences. Memory \& Cognition, 5, 103-110.

KREUZ, R. J. (1987). The subjective familiarity of English homophones. Memory \& Cognition, 15, 154-168.

KuČERA, H., \& FRANCIS, W. N. (1967). Computational analysis of presentday American English. Providence, RI: Brown University Press.

ONIFER, W., \& SWINNEY, D. A. (1981). Accessing lexical ambiguities during sentence comprehension: Effects of frequency of meaning and contextual bias. Memory \& Cognition, 9, 225-236.

Seidenberg, M. S., Tanenhaus, M. K., Leiman, J. M., \& BiEnKowsKI, M. (1982). Automatic access of the meanings of ambiguous words in context: Some limitations of knowledge-based processing. Cognitive Psychology, 14, 489-537.

SWINNEY, D. A. (1979). Lexical access during sentence comprehension: (Re)consideration of context effects. Journal of Verbal Learning \& Verbal Behavior, 18, 645-659.

TABOsSI, P. (1988). Accessing lexical ambiguity in different types of sentential contexts. Journal of Memory \& Language, 27, 324-340.

TAвоssi, P., Cоцомво, L., \& Јов, R. (1987). Accessing lexical ambiguity: Effects of context and dominance. Psychological Research, 49, 161-167.

Tanenhaus, M. K., Leiman, J. M., \& Seidenberg, M. S. (1979). Evidence for multiple stages in the processing of ambiguous words in syntactic contexts. Journal of Verbal Learning \& Verbal Behavior, $18,427-440$.

\section{APPENDIX}

The following is a list of experimental sentences used in this study. All homophones are in italics. Below each sentence are its four lexical targets in the following order: dominant target, subordinate target, dominant control, subordinate control. The percentages after the dominant and subordinate targets are the portions of the pretest population giving that word as the primary associate of the appropriate homophone sense. Polarity ratios for each homophone pair are given at the end of each sentence.

\section{Nonpolar Condition}

1. Jack received many billing notices when he picked up the mail at the post office, but there was nothing from his pen pal. (male) (PR $=1.00$ ) CARRIER 22\% FEMALE $68 \%$ HATRED

2. The physician was unable to visit all of his patients during his morning rounds because he was called away for emergency surgery. (patience) (PR $=.99)$ DOCTOR 68\% VIRTUE 34\% NATION

3. As the two cars collided, both windshields shattered and a piece of flying glass lacerated the driver's hand. (peace) $(\mathrm{PR}=.99)$ PIE 28\% 
4. Michael knew that the thrift shop's clothing was often tattered and worn, so he checked the shirt carefully before purchasing it. (warn) (PR = .99) OLD $16 \% \quad$ WORK
DANGER $19 \% \quad$ DESIRE

5. The century-old oak must have a very strong root system if it survived all these years. (route) $(P R=.97)$ TREE 44\% HIGHWAY 19\% PRICE CONTENT

6.* The ultraviolet rays that come from the sun can burn your skin, so you must be careful outside during the summer. (son) (PR = .95)
MOON 28\%

7. As the boy climbed to the second floor, he tripped on the final stair, twisted his ankle, and was taken to the hospital for X-rays. (stare) (PR = .95) CASE 26\% EYE 31\% CITY END 8. It is widely believe that our sensation of smell is the keenest sense of the five with which we humans are endowed. (cents) (PR =.94)
SMELL 19\% DOLLARS $44 \%$ 9.* The little boy tied his wagon to his bicycle with a cord so that he could pretend to be a conductor with his wagon following him wherever he went. (chord) (PR = .93)
ROPE 22\%
PIANO 23\% RAGE

PIANO 23\%
RAGE

10.* After the bee pollinates the flower, it flies back to its hive

CAKE SORT ROSE 10\%

BAKE $22 \%$ REBEL

11. Bob gets along with all of his relatives, except his Aunt Gloria, whom he has not spoken to for nearly 10 years. (ant) (PR $=.91)$ UNCLE 75\% HILL $26 \%$ SNAKE

12. Environmentally concerned Americans are now aware that their waste must be disposed of properly or it will endanger the planet's future. (waist) (PR $=.90)$ DUMP $16 \%$ HIPS $16 \%$ TYPE DOSE

13. The banks told the real estate developer that without more capital she would not receive the loan and would be unable to begin construction on the new mall. (capitol) $(\mathrm{PR}=.90)$ GAINS $13 \%$ HILL $16 \%$

MEAL TOTAL

14. Tim prefers his meat well-done, so he refused to eat the steak until the waiter brought it back to the kitchen for further cooking. (stake) (PR = .89) MEAT 23\% HEART 16\% NOSE SPIRIT

15. The woman went to the department store and bought a pair of pumps that matched her new evening gown. (pear) (PR $=.89$ ) SHOES $28 \%$ APPLE 39\% JAZZ WITCH

16. The stalk was weighed down by the kernel of the vegetable, giving a slightly flattened look to the entire field. $($ colonel) $(\mathrm{PR}=.88)$ CORN 68\% ARMY 9\% CASH GAME

17. After six months on the diet program, the woman weighed no less than when she started, prompting her to file a lawsuit against the dieting company. (wade) $(\mathrm{PR}=.86)$ HEAVY $23 \% \quad$ WATER $44 \%$ LIKELY SIDE

18. The man began each day with a full breakfast, which included freshly brewed coffee, cereal, fruit, and a donut. (brood) (PR = .85) $\begin{array}{lll}\text { BEER } 47 \% \quad \text { SULK 10\% DISH , and a dont. (brod) (PR } & \text { STRAY }\end{array}$

19. The mechanic had just finished working and was covered with grease, so Mike chose not to shake his hand and hoped he would not take offense. (Greece) (PR $=.85$ ) OIL 13\% ATHENS 16\% TASK FACET

20. Once the telephone repairman climbed the pole, he saw the problem and was able to restore telephone service in just five minutes. (poll) $(\mathrm{PR}=.85$ ) NORTH $28 \%$ ELECTION $13 \%$ THIN TENSION

\section{Polar Condition}

1. A group of children and their parents chanted a holiday carol in front of each house on the block. (carrel) $(P R=.69)$ CHRISTMAS $35 \%$ STUDY $25 \%$ INITIATIVE 2. In a fit of anger, the man kicked the wall, broke his toe, and subjected himself to four weeks on crutches. (tow) $($ PR $=.69)$
FOOT $59 \%$

3. The dog devoured the fruit and buried its core under the fence in our neighbor's backyard. (corps) $(P R=.68)$

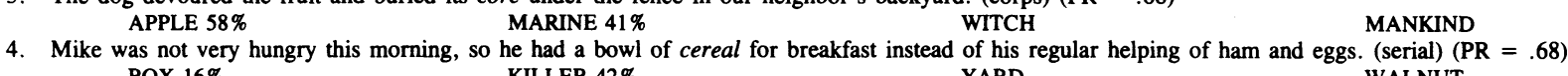
BOX $16 \% \quad$ KILLER $42 \% \quad$ YARD

5. Selling alcoholic beverages to a minor is a punishable offense in most every state. (miner) $(\mathrm{PR}=.66)$ COAL 45\% MOTEL
MAJOR 38\%

6. The hypochondriac complained of a pain in his right shoulder and arm, but the doctor couldn't find anything wrong with him. (pane) (PR = .65) SUFFER 13\% WINDOW 72\% STRIKE FACTOR

7. Jodi was still hungry, so she ate a plum after finishing the five-course meal. (plumb) $(P R=.65)$ PUDDING 23\% DEPTHS 13\% FRECKLE

8. Jack and Mary work in the same office, so he sees her nearly every day in the elevator or in the cafeteria. (seize) (PR = .64)
EYES $22 \%$
TAKE $23 \%$ $\begin{array}{lll}\text { EYES } 22 \% & \text { TAKE } 23 \% & \text { ROOM }\end{array}$

TALENT

9. Whenever I eat peanut butter, it gets stuck on my palate and makes my mouth very dry. $($ palette $)(P R=.63)$ $\begin{array}{lll}\text { TASTE } 48 \% & \text { PAINT } 34 \% & \text { BRANCH }\end{array}$

10. The commander prepared his troop for combat by taking them through the jungles of South America. (troupe) $(P R=.63)$ SOLDIER $13 \%$ DANCE 13\% THEATER ERROR

11. The woman accepted the promotion, because she could not pass up the chance to provide her family with a better life. (chants) (PR $=.61$ ) $\begin{array}{lll}\text { LUCK } 35 \% & \text { MONKS } 19 \% \quad \text { HEEL }\end{array}$

12. It was not his firing that upset Tim, it was the manner in which he was told of his superior's decision. (manor) $(\mathrm{PR}=.61)$ $\begin{array}{lll}\text { WAY } 22 \% & \text { HOUSE 35\% DAY }\end{array}$

13. Bill was dressed very casually, wearing jeans and a ripped $\mathrm{T}$-shirt with his scuffed up sneakers. (genes) $(\mathrm{PR}=.58)$ $\begin{array}{lll}\text { BLUE } 35 \% & \text { BIOLOGY } 16 \% & \text { POOR }\end{array}$

14. The seamstress had not yet sewn the hole in the shirt that she was asked to fix. (sown) $(P R=.57)$

$\begin{array}{lll}\text { HEM } 13 \% & \text { SEED } 29 \% & \text { CODOG }\end{array}$

\section{SCHOOL}

CORONER COFFEE $29 \%$ GOLF $50 \%$ CATTLE BOSS
B

16. After five miles of walking, the soles of my feet began to ache so badly that I was forced to rest for a few moments. (feat) (PR = .56) SHOES 34\% CACOMPLISHMENT 29\% CHIEF CATASTROPHE

17.* Their pet has very fluffy gray fur all over him except on his two front paws and his tail, which are white with spots of black and brown. (fir) (PR $=.55$ ) COAT 23\% TREE 72\% RING LIST

18. The lumberjack spent the afternoon cutting down timber that would eventually be used to build fires throughout the winter. (timbre) $(\mathrm{PR}=.52)$ TREE 25\% SOUND 13\% RULE SPRING 19. Insomniacs often have trouble sleeping through the night and must therefore take medication in order to get sufficient rest. (knight) (PR = .51)
DAY 52\%

20.* Warm weather and salt water make the beach a really fun place to go with your friends to cool off on a hot, sunny day in July. (beech) (PR = .51) $\begin{array}{llll}\text { SAND } 34 \% & \text { TREE 48\% CLERK }\end{array}$ 